\title{
SUPERWOMEN: THE WORK LIFE IMBALANCE
}

\author{
Sonya Church \\ Dept of Sociology and Social Policy \\ University of Waikato
}

\begin{abstract}
Much has been written lately about work life balance. A brief literature review revealed that current work life balance literature focused on the negative effects of imbalance and strategies to overcome it. However, there was a silence in the literature about the impact of imbalance on women's families. Thus, the purpose of this research was to seek the views of three 'high powered' women in paid employment about the effects of their work life imbalance on their families. The research approach was qualitative and three women in long term heterosexual partnerships with children at home and employed as managers in tourism in Rotorua, were interviewed. The data analysis revealed two strong themes: "The negative effects are there but, I am in control and I have great support" and "The lifestyle is worth it." These selected findings are consistent with the literature in that the negative effects are evident in both my findings and in the literature. However, my findings add to the literature because, although the negative effects were identified by the respondents, they do not seem to be a problem. The literature does not acknowledge or discuss this interesting phenomenon. After suggestions for further research, the paper concludes that these women can offer us interesting insights into the work life balance discussion and the milieu within which they make those decisions.
\end{abstract}

\section{Introduction}

Moralists throughout the ages have held that a women's place was primarily within the home and that gender should be the central consideration in determining the role of women within society. During the period of WWI, WWII and the period immediately following, the role of women in society took a dramatic transformation. The expansion of women's activities moved beyond the domestic sphere and into the field of employment. Now well in truly into the new millennium, where is the woman's contemporary role, in the domestic sphere...in the field of employment...or...both?

If modern women are taking on both roles, what is the effect on them and on their families? Women who take on the dual roles of participating in the employment field as well as the domestic sphere tend to suffer an imbalance within their lives. Are these women superwomen fighting and winning the battle of imbalance, or victims of the imbalance?

A short literature review revealed that current work life balance literature focused on the negative effects of imbalance and strategies to overcome it. There were three main negative effects that women suffer from, these include, physical, emotional and social effects. There were two coping strategies; one was an educational type programme and the other, childcare provisions.

This report draws on the silence within the literature about these negative effects of the imbalance on the women's family and home life. Thus, the purpose of this research was to seek the views of three 'high powered' women in paid employment, with families at home, about the effects of their work life imbalance on their families. The paper first presents and then critiques existing literature. Second, the paper turns to focus on the research design and the data collection. Third, it will present the selected findings of the data collection. Fourth, the paper turns to a broad discussion before finishing with a brief conclusion.

\section{Critique of Existing Literature}

A brief literature review revealed that current work life balance literature focused on the negative effects of imbalance and strategies to overcome it. There are several problem areas within the literature which the paper will address in turn. First, the negative tone in the literature ignored possibilities that women experience imbalance positively. Second, the literature seemed to assume that women are a homogeneous category. Third, the coping strategies that were provided by the literature seemed weak and did not appear to have any long term solidarity or prevention solutions. Finally the negative effects on the family were not explored fully.

Negative tone ignored possibilities that women experience imbalance positively: Although the literature located for this research was well written and informative, most work life imbalance issues do not focus on women directly. A definition provided by Hutton (2002) states, that work-life balance is for all, not just women, but as uncovered in this literature review, women are carrying with them a lot more burdens and negative effects than most men. But, the literature failed to acknowledge the possibility that the imbalance was not a problem to a lot of women in the workforce, but actually just part of the daily routine.

There was an element of encouragement for women by women (authors) to hang in there. Is this a hint of the negative effects being ok? One piece of literature finished with this statement, and I thought it captured the encouragement for women very well, "the example of a 
'few good women' of the past and the 'few excellent women of the present', is set to inspire the 'many excellent women' of the future." (Spackman, 2003, p. 19).

Assumed that women are a homogeneous category: The majority of the literature reviewed was written by women from a critical perspective. This could have a negative impact on the imbalance that women suffer, as it assumes all women feel this way. Male authors were a majority surrounding work life balance issues, but when it came to being directly related to women and the imbalance they suffer, the authors were predominantly female. The literature failed to mention women with disabilities, different ethnicity, colour, race, sexual etc; all of these issues were ignored. As mentioned above, the literature failed to acknowledge any positives or that the effects outlined might not be a problem for all women encountering an imbalance.

Coping strategies were weak with no solidarity: There were two coping strategies provided by the literature, the first of the two coping strategies was an education type programme. This programme included education where the parents are taught strategies to cope with the stress of the imbalance of raising a family as well as the stress of full time employment. It offered different programmes for employed parents with children at different ages and stages of life (Stallmman \& Saunders, 2004). The literature implied that this was an excellent coping strategy for parents who are not coping with an imbalance. This coping strategy is like the 'ambulance after the accident', rather than a preventative. This coping strategy is not solving the problem of imbalance and the effects that occur as a result, it is more like prolonging the inevitable (negative effects). It is not directly reducing the negative effects that the women may suffer or reducing the chance of those effects overlapping into the women's family life.

The second coping strategy for women to overcome the imbalance was the provision of childcare subsidies/options. This coping strategy offers women who suffer an imbalance the option of having someone to care for their children either inside or outside of the home. This strategy is not going to prevent effects of the imbalance on the family either. These two coping strategies open a whole new 'can of worms', as the parents are still not in the home. This is an important issue that the literature did not cover, as the family environment is a breeding ground for emotions and responsibilities (Myers, 1994). Employing a caregiver for family duties cannot solve the need for a balance between work life and family life roles.

The literature spoke about the negative effects and "losing the spark" (Hansen, 2001, p.4), but unfortunately, it failed to offer any solid avenues for women to go down or any long term strategies. The literature did not look into any future or any long term solutions, such as, men meeting women half way, that is, no gender segregation between 'men's work' and 'women's work', where all roles are shared equally in and out of the home. The literature gave little regard to children and how the negative effects that women suffer affect their children and family life.

Effects on the family not explored fully: Women are burdened, not only with being the primary caregiver and domestic labourer, but they also have to juggle their time with being one of the family providers, as well as, still being seen secondary to men and having to live up to (or down to?) social expectations. No matter which way you look at it, some women are by far 'multi-tasked professionals'...or should I say 'superwomen'! Although the literature brought into light that some women are amazing, it also highlighted that being amazing does not come without its burdens and negatives.

As you can see so far, the literature has uncovered three main negative effects suffered by women as a direct result of the work slash family life imbalance; there was a silence in the literature about the impact of that imbalance on women's families.

The silence in the literature could leave the assumption that there is no overlap of the negative effects into family life. This moves into the area of the current research. Do the women within these professional positions see these negative effects and do these negative effects overlap into their family life? If they do, what is the impact of that overlap, and is it worth it?

\section{Research Design and Data Collection}

Given the above discussions, the specific research question for this study was:

What are the views of three 'high powered' women in paid employment about the effects of their work life imbalance on their families?

This research project took a qualitative approach. Such an approach was ideal to uncover the necessary information and enable the interviewer to identify the nature of the effects and probe for deeper meanings, assumptions and hidden views. All three respondents were women who self-identified as having lives out of balance. They were in long term heterosexual relationships with young children aged from 2-17 years, living at home. All three respondents were managers in tourism in Rotorua and worked 50 hours plus per week. Their male partners (two of the women were married, one was in a long term defacto relationship) were employed from 23-40 hours per week in semi-flexible positions.

The nature of the questions asked in the interviews, were to identify any effects either positive or negative as a result of an imbalance. The questions draw on the effects identified by the respondents and then further probed to unleash any overlap into the woman's family life.

Data analysis consisted of transcribing taped interviews. Once the taped interviews were transcribed, phrases and sentences were grouped into robust clusters which were formed into themes relating to the research question.

This procedure is common with qualitative methods and was carried out in a continuous comparative method 
resembling grounded theorisation. Final themes were representative of the core responses uncovered in the interviews.

\section{Selected Findings}

My data analysis revealed two strong themes: First, "the negative effects are there but, I am in control and I have great support" and second, "the lifestyle is worth it." These two themes are broadly arranged, with a number of subcategories.

\section{Theme One}

\section{The negative effects are there but, I am in control and have great support}

The effects identified by the respondents were mostly negative and are congruent with the three main negative effects found in the literature, social, physical and emotional effects.

I am in control: There was an undoubtedly strong sense of control from all of the respondents. There was a great sense of control of the work place, control of their families well being and control of their imbalance.

Working environment: The respondents were in control of their working environment, as Maltilda said,

I don't give my employer a choice, I use the words 'I am', not 'can I'. I make it work for me. I don't care about family friendly policies, I don't think there is a need, and we all just do what we have to. There is no rule, but there is no problem either, if my child is sick, I would just go. I use the fact that I work more than I should to my advantage.

This control (where applicable) extended to employees under their control, there was no need for family friendly policies etc for staff as these women were in control and felt as women, that they were fair and understanding in their judgment calls.

Monitored families well being: All three respondents claimed they would give it all up if their family showed signs of not coping with their imbalance. The women all seem to be aware of their families wellbeing, that is if they are coping of not. As Kath said,

My house burnt down three months ago; I was away at the time. I did not think my youngest son of three years would let me go away again three weeks later, after moving into a strange house. But he seemed fine, so I felt I was able to go.

Maltilda claimed, "my kids are super independent, because I have made them that way, I just work and cook, they do not miss out, and they have their father".

Themselves: The women were constantly in control of, where their families were at, physically and mentally. They were also monitoring themselves, as Kim claims,
When I start tensing up and stress out and yelling and screaming at everybody, I put up a barrier up for a while, I withdraw and throw myself into mindless tasks, like house work, until I am in a better frame of mind to deal with them.

Control of imbalance: The control of the imbalance was an interesting phenomenon to uncover! Two of the women (Kim and Maltilda), claimed they were in control of the imbalance, as Kim said "you have to be realistic, and have a good understanding of the expectations and then balance them, if I could not balance them, then I would not be here". Maltilda said, "I don't do the "poor me, poor me' thing, this is just how it is". Where as Kath said, "once you get your head around the fact that you don't manage, that you will never manage again, everything is fine". Kath's idea of controlling the imbalance is slightly different from Kim and Maltilda's, as she claimed she controls her imbalance by telling her self it is ok not to have everything 'perfect' and you have to expect things not to go to plan, but none the less, still a method of control.

I have great support: All three women claimed they would not take on so much without the support of their husbands, family members and friends.

Husbands: The support of their husbands/partners was invaluable and what is very interesting here is that all three women felt 'lucky' to have their support. As Maltilda said, "I am lucky because my husband cares; he does everything". Kath... "The major load is the woman's, but I am lucky to have my husband, he is the wind beneath my wings". And Kim 'bragged', "I am lucky because I have the support of my family in Rotorua. The husbands/partners were employed in blue collar semi-flexible positions (postie, mechanic and arborist) where they could be called upon "if it all turns to custard" (Kath).

Friends: Friends are another very important support network for all three women. As part of a coping strategy two of the women, Kath and Kim needed support from friends in similar circumstances. All three women claimed to smoke, drink and swear far too much, but looked forward to mixing with friends on a weekly basis. Kim stated, "I like to socialize with friends within similar pressures, to offload to someone who understands, it makes you feel normal". Kath... "I have and need a good support network of friends around me".

Family: Finally, this research shows that there is also a need for family/whanau support. Maltilda said, "I would not do it without support that would be just dumb. There would be no point". Kath... "If I wasn't in a supportive environment, it would probably be a different story". Kim said, "I am lucky to have my family; I could not do it without them, as the impact on my family would be worse if they did not have family to go to. I would not do it".

All three women claimed that they would not do what they do without the support of all three support networks, 
friends, family and husbands/partners. As you can see, the support networks seem to be their 'rocks'.

\section{Theme Two}

\section{The lifestyle is worth it}

The second strong theme that the research drew out was that the life style was worth it.

Rewards for the family: Maltilda said "this is a life style choice of hard work and giving up, I do this because it is my choice, I don't have to do this, my kids have never missed out because of my employment".

Kath explained that "we have an amazing life style; the money that you earn allows you to make decisions for your kids and you, which are privileges that other people around you would not necessarily get".

The privileges that Kath spoke of included private education, travel and fine cuisine. Kim said, "your family need to know that they can not have the clothes they wear, or do the things they do if their mother did not do this level of employment".

Rewards for herself: "I have done all the hard work (study), so I am reaping the rewards now". This is how Maltilda described the rewards from her employment position. Kath said, "I love buying shoes and going overseas". Kim claimed "it's the friendships". All three respondents said there was a high level of reward/satisfaction from 'the buzz' of what they do. Also, the socializing has a great sense of reward for the women, drinking with friends in similar positions.

\section{Discussion}

The most interesting part of this study is that the negative effects were not an issue. The negative effects just seemed to be part of the life style these women chose. These selected findings are consistent with the literature in that the negative effects are evident in both the findings of this research and in the literature. However, the findings add to the literature because, although the negative effects were identified by the respondents, they do not seem to be a problem. The literature does not acknowledge or discuss this interesting phenomenon.

These women were not out to control or prevent the ncgative effects, rather accepted them as part of their daily routine. All three women in this study claimed that they chose to have the negative effects, "it is written on the label of the job" (Kath).

Another interesting phenomenon was that all of the women's husbands/partners were in blue collar employment. Their employment consisted of, a mechanic, a postman and an arborist. The mechanic owned his own business, therefore was able to help out in emergencies with the children. The postman worked only 23 hours per week, so he could be there for the children and do all of the houschold chores. The arborist finished work early every day to pick the children up from their private day care. This is interesting as one could assume that the spouse of a women employed in a high powered position would also be in a high powered position himself.

As my research has shown, the women could not, or would not do what they do if they did not have the support of their husbands/partners. Having supportive, flexible husbands/partners is one way to cope with the imbalance that these women suffer. On the other hand, would these women still do what they do if they had a supportive husband, but not a flexible one, for example, a husband in a high powered position?

Another interesting phenomenon is that tourism in Rotorua, where women were employed, is largely based on the Maori culture. All three women appeared to be of Maori decent (not a question asked in current research). Therefore, their 'balance of the imbalance', may be based in cultural values, for example, support of family/whanau and friends.

The cultural values may also have an effect on how the women constantly monitored their families well being, it is all about support and wellbeing of the larger group.

These women did not feel that their family or children suffered as a result of their imbalance, they claimed that it was hard at times, but that "it all panned out in the end" (Kath). They all felt that they were being good role models for their children, showing them "if you want something, go out and get it" (Maltilda).

The three strongest words the women used to describe their imbalance were, juggling, battling and stretched. These women saw themselves as normal hard working citizens, no better than the next person. They did not think they were amazing in any way or that they suffered more than any body else, "there is always someone worse off" (Kath). All three women claimed to be EXTREMELY organized and had independent personalities.

For future research directions, I would like to see the same question asked, but with lower socio-economic women. For example, I wonder if women in retail positions, earning a lot less than the 'high powered woman', with a husband/partner also in full time employment, would have the same views as the three women in the current study. I wonder if the imbalance would be worthwhile without all the privileges and rewards.

Also, I wonder how the male partners view their partners' imbalance. Would their views be the same as the women's? Is the life style worth it? I would also like to see a longitudinal study of long term affects of the imbalance on the family and on the women.

In summary the selected findings are consistent with the literature in that the negative effects are evident in the research and in the literature. However, the current selected findings add to the literature because, although the negative effects were identified by the women interviewed, they do not seem to be a problem. The literature does not acknowledge or discuss this issue. 


\section{Conclusion}

Some women have come from being seen as secondary to man and their place in society being solely within the home, to being 'high powered' 'managers and bosses' within the employment arena (amongst other achievements). Women are now participating in the employment field as well as still being in charge of the domestic, care giving duties. Thus, women in full time employment suffer an imbalance in their lives between employment and home life. Hence, the purpose of this research was to seek the views of three 'high powered' women in paid employment about the effects of their work life imbalance on their families.

The data analysis revealed two strong themes: "The negative effects are there but, I am in control and I have great support" and "The lifestyle is worth it." These selected findings are consistent with the literature in that the negative effects are found in both my findings and within the literature. However, my findings add to the literature because, although the negative effects were identified by the respondents in the current research, they do not seem to be a problem to them.

The literature does not acknowledge or discuss this interesting phenomenon. This interesting phenomenon may have other contributing factors, such as, cultural values. I think that these women can offer us interesting insights into the work life balance discussion and the milieu within which they make those decisions.

\section{References}

Hansen, A. (2001). Signing On. Employment today. 90: pp. 1-5.

Hutton, P. (2002). Working Flexibility. Employment today. 76 : p. 28.

Myers, D. (1994). Exploring social psychology. U.S.A: McGraw-Hill

Spackman, K. (2003). A Few Good Women. Employment today. 83: pp. 18-19.

Stallmman, H., \& Sanders, M. (2004). Balancing Work and Family. Employment today, 90: p. 29. 